The Distributive and Welfare Effects of Product and Labour Market Deregulation

Gabriele Cardullo

DIEM, Faculty of Economics, University of Genoa, Via Vivaldi 5, Genova (Italy). 


\title{
The Distributive and Welfare Effects of Product and Labour Market Deregulation
}

\author{
Gabriele Cardullo \\ DIEM, Faculty of Economics, University of Genoa, Via Vivaldi 5, Genova (Italy).
}

\begin{abstract}
This paper studies the effects of product and labour market deregulation on wage inequality and welfare. By constructing an analytically tractable model in which the level of product market competition and the wages are endogenously distributed among sectors, I show that deregulation in goods market has mixed effects on inequality: the wage variance and the Gini index are lower, but the ratio of the highest over the lowest wage paid in the economy increases. Moreover, deregulation in labour markets raises the aggregate level of employment and the average real wage but reduces the welfare of trade unions in sectors with a low level of competition.
\end{abstract}

Keywords: product market competition; wage distribution; barriers to entry.

JEL codes: E24, J5, L16 


\section{Introduction}

In recent years a large theoretical and empirical literature has stressed the beneficial effects of product and labour market deregulation on employment and the real wage. However, the adoption of these policies has often encountered the vehement opposition of lobbies, interests groups, unions, and simple citizens. Several arguments can be brought to explain this attitude. It can be viewed as a confirmation of a status quo bias, a tendency not to embrace change that does not necessarily runs afoul of rational decision making ${ }^{1}$. Opposition may also depend on some myopic behaviour, since some of the benefits that deregulation may deliver are not immediate or difficult to perceive beforehand ${ }^{2}$.

This papers tries to offer an alternative view. These policies may well increase employment and the real wage, but product market deregulation has mixed effects on wage inequality and labour market deregulation can reduce trade unions' welfare.

As concerns wage inequality, product market deregulation, captured by a reduction in the cost of entry in the product market, delivers two conflicting results. Tougher competition in the goods market implies that more workers are employed in sectors with many firms, and so more employees earn the same wage, decreasing the wage variance. However, it allows the existence of sectors with stronger competition and low-paid jobs, widening the distance between the highest and the lowest wages in the economy.

Labour market deregulation - formally represented by a decrease in the bargaining power of workers' unions - may reduce their welfare because it increases the probability that new firms will enter the market, shrinking the incumbents's expected profits and wages. This negative effect is stronger the less competitive is the product market. So, in sectors with poor competition in the goods market unions are worse off, despite the employment and real wage gains.

These results are obtained by nesting in a model with imperfect competition in

\footnotetext{
${ }^{1}$ Samuelson and Zeckhauser (1988) discuss the cognitive and psychological explanations for the status quo bias. Even Fernandez and Rodrik (1991) claim that resistance to reforms springs from ex ante uncertainty about who will be the individual gainers or losers.

${ }^{2}$ Workers may focus only on nominal wage variations and neglect changes on the price of the consumptions goods.
} 
both the goods and the labour market two distinctive features: at the equilibrium, (i) the level of competition is not the same in all sectors of the economy and (ii) in each one it varies according to an endogenous stochastic process. The model is analytically tractable and welfare and inequality outcomes are derived in general equilibrium.

Specifically, the product market has a two-tier structure, with one final consumption good sold in a competitive market and a large number of intermediate goods sectors, identical ex ante, in any of which Cournot competition prevails. As respects to labour market, unions of firms and workers bargain over the wage at sectoral level. The creation and the destruction of firms in each intermediate market follow a continuoustime Markov Chain, in which the entry of a new competitor is determined by a zero profit condition and the exit rate is exogenous. At the steady-state equilibrium, the level of competition, the real wage, and the level of employment vary stochastically within each sector and follow an endogenous distribution at the aggregate level.

Comparative statics provides some clear-cut results: product and labour market deregulation raise the aggregate level of employment. Most of the welfare and inequality effects are obtained by calibrating and simulating the model for Belgium, a small open economy that epitomizes many characteristics of product and labour markets in Western Continental Europe. The OECD has constructed several indicators to measure the extent of regulation of its members ${ }^{3}$. As concerns the barriers to entrepreneurship, Belgium has an index of 1.428 (France has 1.284 and Germany 1.315), ranking third among Western European countries (only Greece and Luxembourg are more regulated). With a score of 3.735, Belgium also has the strictest legislation governing the retail sector among all OECD countries except Luxembourg (France gets 3.11 and Germany 2.438). In terms of strictness of employment protection, Belgium has an index of 2.18, above the average OECD country of 1.94. Finally, Belgian unions play a crucial role in the wage negotiation, with $96 \%$ of employees covered by collective agreements. ${ }^{4}$

An interesting feature of the calibration concerns the wage distribution. Identical workers earn different salaries only because they are in sectors with different degrees of product market competition. By parameterizing the rates of creation and destruction of firms on the basis of employment and business data, the resulting wage density has an

\footnotetext{
${ }^{3}$ The rankings for the 2008 are available at http://stats.oecd.org/Index.aspx.

${ }^{4}$ See the ICTWSS database (January 2009, available at http://www.uva-aias.net/207).
} 
empirically accurate shape: unimodal and positively skewed. Without the pretension to consider competition in goods market the main source of earnings inequality, this result may be an useful piece of information for a better understanding of it.

The literature on the effects of product and labour market deregulation is large and varied. As concerns the theoretical side, Blanchard and Giavazzi (2003), Carlin and Soskice (2006), and Ebell and Haefke (2009) show that such policies have beneficial effects both on employment and the real wage. Spector (2004) contends that product market competition actually depresses the real wage if capital and decreasing returns to labor are accounted for, since workers find harder to appropriate the quasi rents caused by the partial irreversibility of capital investment. Recent empirical studies on a sample of OECD countries (Nicoletti and Scarpetta, 2005, Fiori et al., 2008 ) confirm Blanchard and Giavazzi's basic predictions on employment. Griffith et al. (2007) also find a positive effect of product market deregulation on the real wage.

All the above-cited theoretical papers evaluate the impact of such reforms in a context of monopolistic competition in goods market and some sort of labour market imperfection (unionization or search frictions) ${ }^{5}$. However, unlike this paper, they consider a symmetric and deterministic equilibrium, in which each sector is indistinguishable from the others and the degree of competition takes an endogenous deterministic value. The stochastic structure of the present work allows to focus on distributional issues and enriches the welfare analysis: by incorporating in unions' utility function the endogenous probability of a change in competition, their welfare may decrease in response to a policy, despite a positive effect on employment and the real wage.

While there exists a large literature studying the impact of labour institutions on the wage distribution ${ }^{6}$, less attention has been devoted on the interplay between product market competition and earnings inequality. Guadalupe (2007) tries to fill this gap, but from a different angle ${ }^{7}$. While in the present paper wage differentials

\footnotetext{
${ }^{5}$ In Blanchard and Kiyotaki (1987), a similar model is constructed to study the relation between real money balances and real aggregate consumption expenditures. See also Lehmann and Van der Linden (2010) for a model with a matching technology in both the good and the labour market.

${ }^{6}$ See Koeniger et al. (2007), Card et al. (2004), and DiNardo et al. (1996).

${ }^{7}$ Another paper is Jean and Nicoletti (2004). They find that anticompetitive regulations increase wage premia in non-manufacturing industries.
} 
arise only between sectors, Guadalupe focuses on within-sector wage inequality. In her model, tougher competition in goods market makes firms more eager to hire high-skilled workers, that are capable to produce at lower costs. So returns to skill are higher in more competitive markets, increasing within-sector wage differentials.

As concerns the role of unions in regulated labour markets, the paper resembles Delacroix (2006). He develops an equilibrium matching model with monopolistic competition in goods market and in which only some labour markets are unionized. Such a framework allows to contrast the performance of markets with different degrees of collective bargaining coverage, union coordination, and centralization in the wage setting process. Unlike the present work, the focus is more on the correlation between generous unemployment benefits and unionization than on deregulation policies.

The structure of the paper is the following. Sections 2 and 3 illustrate the model and the steady-state equilibrium. Section 4 presents the comparative static results. Sections 5 and 6 respectively show the calibration and the simulation results. Section 7 discusses some different assumptions on unions' preferences. Section 8 concludes.

\section{The model}

\subsection{Preferences and technology}

I consider an economy with one final consumption good and a large integer number $I$ of intermediate goods. The final good market is perfectly competitive, whereas Cournot competition is assumed within each intermediate sector. The final good production function takes a CES form:

$$
Y=\left[\sum_{i=1}^{I} Q_{i}^{\frac{s-1}{s}}\right]^{\frac{s}{s-1}}
$$

in which $Q_{i}$ is the amount of intermediate good $i$ used by the production process of the final good and $s>1$ to allow a situation in which some $Q_{i}$ are equal to zero. Cost minimization in the final good sector leads to the inverse demand for each intermediate good $i$ :

$$
p\left(Q_{i}\right) \equiv \frac{P_{i}}{P}=\left(\frac{Q_{i}}{Y}\right)^{-\frac{1}{s}} \quad \text { with } P \equiv\left[\sum_{i=1}^{I} P_{i}^{1-s}\right]^{\frac{1}{1-s}}
$$

$P$ is the price index. Parameter $s$ is the elasticity of the demand for good $i$. 
Time is continuous. In each intermediate sector there is a measure normalized to 1 of workers; they can be employed only in that industry, so there are $I$ perfectly segmented labour markets ${ }^{8}$. The number of firms competing in each intermediate sector follows a Markov chain that will be described in the next section. The intermediate firm production function is identical in each sector and is given by $l_{j, i}$, the labour input for firm $j$ in sector $i$. The total amount of good $i$ produced is therefore equal to the level of employment in that sector and is denoted by $Q_{i}=\sum_{j} l_{i, j}$.

Workers' unions enjoy an instantaneous utility equal to $w_{i} \cdot \sum_{j} l_{i, j}+z \cdot\left(1-\sum_{j} l_{i, j}\right)$, with $w_{i}$ and $z$ respectively being the real wage paid in sector $i$ and the value of home production. The instantaneous utility of the unions of firms is given by the sum of each firm's profits.

A crucial assumption of the paper is that the value of what is produced at home by the unemployed is a fraction of the total market output: $z=\alpha \cdot Y$, with $0<\alpha<1$. This is a simple condition whose empirical plausibility is difficult to either reject or justify, since we lack times series data for home production. ${ }^{9}$ The rationale for this choice is that it introduces in a very clear manner a procyclical opportunity cost of employment. The model is thus able to study the interaction of two opposite forces that affect firms' decision. A higher total output not only raises the demand for the intermediate goods but also exerts pressure for wage increases ${ }^{10}$. As I proceed, I will clarify the general equilibrium implications of the presence or absence of this second effect.

\footnotetext{
${ }^{8}$ The assumption of perfect segmentation in the labour markets is essentially done for tractability reasons. Still, one can think that the tasks and abilities required to work in a industry are so specific that it is very expensive to switch from one sector to another. Some empirical literature (e.g. Neal, 1995 and Parent, 2000) goes in this direction, showing that the skills the market rewards most are neither firm specific nor generic one but industry specific.

${ }^{9}$ Recent studies (Blankenau and Kose, 2007) do not find a clear correlation between home production and GDP while suggesting that the former may be more volatile than the latter.

${ }^{10}$ For a similar purpose, Blanchard and Giavazzi (2003) impose that the opportunity cost of employment negatively depends on the unemployment rate. In a textbook matching model (Pissarides, 2000, p 20-21), home production is proportional to the wage to avoid that increases in market production translate into a lower unemployment rate, something odd in a long-run perspective. The assumption of this paper weakens (but does not eliminate) the positive correlation between market production and employment.
} 


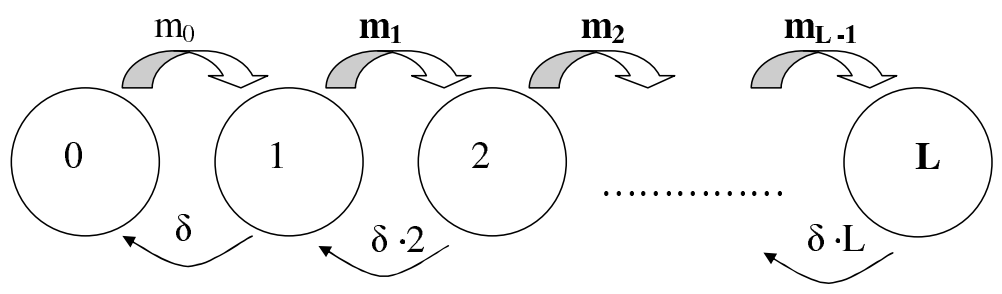

Figure 1: Creation and destruction of firms. In bold the endogenous variables.

\subsection{The Stochastic Environment}

The creation and destruction of firms in each intermediate market $i$ follow a continuous time Markov chain that takes values in the set $L=\{0,1,2, \ldots L\}, L$ being the maximum number of firms that can compete in a sector. I assume that in small interval of time $d t$ at most one firm can enter or leave a sector. So, if $x_{i}$ is the number of firms active in sector $i$, there is a probability $m_{x_{i}} d t$ that a new firm enters and a probability $\delta \cdot x_{i} d t$ that one firm exits (see Figure 1$)^{11}$.

I impose $m_{x_{i}}=q \cdot V_{x_{i}}$, with $V_{x_{i}}$ being the measure of firms that want to enter in sector $i$ when there are already $x$ incumbents. At $x=L$, firms have no incentive to enter the market and $m_{L}=0$. Both $V_{x_{i}} \forall x_{i} \in[1,2, \ldots L]$ and $L$ are endogenously determined by zero profit conditions in entry behaviour. As it will be more clear later on, for simplicity reasons I find convenient to impose $m_{0}$ as a constant.

Since intermediate sectors are identical ex-ante - they have the same level of labour force, the same preferences, and technology - the subscript $i$ can be removed. Let $\pi_{x, t}$ be the probability that at time $t$ there are $x$ active firms in a generic intermediate market. Then:

$$
\begin{aligned}
\pi_{x, t+d t}= & {\left[1-\delta \cdot x d t-m_{x} d t\right] \cdot \pi_{x, t}+m_{x-1} d t \cdot \pi_{x-1, t} } \\
& +\delta \cdot(x+1) d t \cdot \pi_{x+1, t} \quad \forall x \in[0,2, \ldots, L] .
\end{aligned}
$$

Henceforth, the model will be developed in steady-state. The steady-state probability distribution is such that $\pi_{x, t+d t}=\pi_{x, t}, \forall t$. Expressing $\pi_{x}$ in terms of $\pi_{x-1}$ yields:

$$
\pi_{x}=\frac{m_{x-1}}{\delta \cdot x} \cdot \pi_{x-1} \quad \text { with } x \in[1,2, ., L] .
$$

\footnotetext{
${ }^{11}$ This Markov chain is called a birth-death process. See Taylor and Karlin (1998) for details.
} 
Since $\pi_{0}=1-\sum_{n=1}^{L} \pi_{n}$, one obtains:

$$
\begin{aligned}
& \pi_{x}=\frac{\left(\frac{1}{\delta}\right)^{x} \cdot \prod_{n=0}^{x-1} \frac{m_{n}}{n+1}}{1+\sum_{j=1}^{L}\left(\frac{1}{\delta}\right)^{j} \cdot \prod_{n=0}^{j-1} \frac{m_{n}}{n+1}} \quad \text { with } x \in[1,2, ., L] \\
& \pi_{0}=\frac{1}{1+\sum_{j=1}^{L}\left(\frac{1}{\delta}\right)^{j} \cdot \prod_{n=0}^{j-1} \frac{m_{n}}{n+1}}
\end{aligned}
$$

The probability $\pi_{x}$ that in one intermediate sector there are $x$ firms competing in the market depends on $\delta$ and the endogenous values $L$ and $m_{n}=q \cdot V_{n} \quad \forall n \in$ $[0,1,2, \ldots L-1]$. With $I$ sufficiently large, I can apply the law of large numbers and define the aggregate level of employment

$$
E=\sum_{x=0}^{L} l_{x} \cdot x \cdot \pi_{x} \cdot I,
$$

in which $l_{x} \cdot x$ is the total amount of labour employed in a sector with $x$ firms.

\subsection{Wage determination}

In each intermediate sector, unions of firms and workers bargain over the wage. Such an assumption seems plausible for many countries in Continental Europe, where the sectoral level of negotiation often plays a major role ${ }^{12}$.

Let $r$ be the discount rate common to all agents. The expected discounted utility of the unions of workers is:

$$
\begin{aligned}
& r U_{W}(x)=w_{x} \cdot l_{x} \cdot x+\alpha \cdot Y \cdot\left(1-l_{x} \cdot x\right)+m_{x}\left[U_{W}(x+1)-U_{W}(x)\right] \\
& +\delta \cdot x\left[U_{W}(x-1)-U_{W}(x)\right]
\end{aligned}
$$

with $x \in[0,1, \ldots, L]$. Operating as a union of workers in market with $x$ firms is like holding an asset that pays you a dividend equal to the sum of the wages paid to the employees and the income earned by the unemployed. The underlying assumption is that the trade union behaves in a utilitarian way, caring about the sum of its members' incomes. The evaluation of the welfare of trade unions being one of the objectives of this paper, this condition and the one of purely sectoral unions will be specifically

\footnotetext{
${ }^{12}$ In Belgium the sectoral level is predominant, even if in recent years new agreements have taken place. See Brock and Dobbelaere (2006).
} 
studied and relaxed in section 7 . At certain rates, the level of competition may decrease or increase by one unit, modifying the asset value to $U_{W}(x-1)$ and $U_{W}(x+1)$. The expected discounted utility of a union of firms is:

$$
\begin{aligned}
& r U_{F}(x)=x\left[p\left(Q_{x}\right) l_{x}-w_{x} l_{x}\right]+m_{x}\left[U_{F}(x+1)-U_{F}(x)\right] \\
& +\delta \cdot x\left[U_{F}(x-1)-U_{F}(x)\right]
\end{aligned}
$$

with $x \in[1,2, . . L]$. Function $p\left(Q_{x}\right)$ is expressed in $(2)$ and represents the price of the intermediate good when $x$ firms are competing in the market.

I consider an axiomatic Nash solution. The real wage received by the employees in a sector with $x$ active firms solves the problem:

$$
\begin{aligned}
& w_{x}=\operatorname{argmax}\left[U_{W}(x)-\bar{U}_{W}\right]^{\beta}\left[U_{F}(x)-\bar{U}_{F}\right]^{1-\beta} \\
& \text { s.t. } \\
& U_{W}(x)>\bar{U}_{W} \\
& U_{F}(x)>\bar{U}_{F} \quad \text { with } x \in[1,2, . . L] .
\end{aligned}
$$

The terms $\bar{U}_{F}$ and $\bar{U}_{W}$ denote respectively the threat points for the unions of firms and workers. I impose $r \bar{U}_{F}=0$ and $r \bar{U}_{W}=\alpha \cdot Y$. If no agreement is concluded, the employees in that sector do not work and earn the same fraction of the consumption good of the unemployed workers. The firm does not produce and does not pay any wage $^{13}$. The constraints imposed in the maximization mean that both parties have always the possibility to abandon the negotiation if this choice makes them better off. As in Rosen (1997) and Hall and Milgrom (2008), they are not binding: no player has an incentive to quit the negotiation and this holds for any value of $x$.

Computing the F.O.C. and using (6), (7), and the conditions on the threats points yields:

$$
w_{x}=\beta p\left(Q_{x}\right)+(1-\beta) \alpha \cdot Y \quad \forall x \in[1,2, \ldots, L] .
$$

The wage is a weighted average of the total revenues obtained in the intermediate sector

\footnotetext{
${ }^{13}$ Such threats points are similar to those introduced by Rosen (1997) and Hall and Milgrom (2008). The idea is that a disagreement in the negotiation between unions usually implies a delay in the production, strikes, not massive lay-offs or quits. Actually, in the paper of Hall and Milgrom, the delay in the production involves a flow cost for the firm. For simplicity, I impose it equal to zero.
} 
$\left(p\left(Q_{x}\right) l_{x}\right)$ and the opportunity cost of employment $(\alpha \cdot Y)$. The weights are given by the bargaining power of workers and firms, $\beta$ and $1-\beta$.

\subsection{The Cournot game}

Conditional on the wage equation (9), at each point in time, a firm decides the optimal level of labour input to play the Cournot game. The expected lifetime income for a firm producing in a market with $x-1$ competitors solves the following problem:

$$
\begin{gathered}
r J_{E}(x)=\max _{l_{x}} p\left(Q_{x}\right) l_{x}-w_{x} l_{x}+\delta(x-1)\left[J_{E}(x-1)-J_{E}(x)\right] \\
+m_{x}\left[J_{E}(x+1)-J_{E}(x)\right]-\delta J_{E}(x) \\
\text { s.t. } w_{x}=\beta p\left(Q_{x}\right)+(1-\beta) \alpha \cdot Y
\end{gathered}
$$

Operating in a such a sector pays you a dividend of $p\left(Q_{x}\right) l_{x}-w_{x} l_{x}$, the revenues net of the wage bill. At a rate $\delta \cdot(x-1)$, one of the competitors exits the market, while at a rate $m_{x}$, the number of firms active in the market increases by one unit. Finally, at a rate $\delta$ the firm itself exits the market, experiencing a capital loss equal to $-J_{E}(x) .{ }^{14}$

The F.O.C. of the problem is:

$$
\alpha \cdot Y=\left[p^{\prime}\left(Q_{x}\right) l_{x}+p\left(Q_{x}\right)\right]=p\left(Q_{x}\right)\left[1-\frac{1}{x \cdot s}\right]
$$

The second equality is obtained by using equation (2). As common in a $x$-players Cournot game, each firm maximizes its surplus given the optimal strategy of the others. In equilibrium, the marginal revenue of a firm must be equal to the marginal utility of unemployment ${ }^{15}$. Notice also that any firm takes the amount of the final good, $Y$, and the price index $P$ as given (see Dixit and Stiglitz, 1977).

Since firms in the same sector hire the same level of labour input, $Q_{x}=x \cdot l_{x}$. From (2) and (11), the equilibrium level of $l_{x}$ is:

$$
l_{x}=\frac{Y}{x} \cdot\left(\alpha \cdot Y \frac{x s}{x s-1}\right)^{-s} \quad \forall x \in[1,2, \ldots, L] .
$$

\footnotetext{
${ }^{14}$ This is tantamount to saying that the expected discounted utility of a firm that is outside the market is equal to zero.

${ }^{15}$ Differentiating equation (11) with respect to $l_{x}$, I obtain $\left[p^{\prime \prime}\left(Q_{x}\right) l_{x}+2 p^{\prime}\left(Q_{x}\right)\right]$ that is negative if $\frac{1+s}{s}<2 x$. This is always true for any $x \geq 1$ and $s>1$.
} 
By using equation (11), I can write the wage equation as a function of $Y$ only:

$$
w_{x}=\alpha \cdot Y \cdot \frac{\beta+x \cdot s-1}{x \cdot s-1} \quad \forall x \in[1,2, \ldots, L] .
$$

Finally, using (9), (11), and (12), firms' revenues can be written as

$$
p\left(Q_{x}\right) l_{x}-w_{x} l_{x}=\frac{(1-\beta)}{x(x s-1)} \alpha^{1-s} \cdot Y^{2-s}\left(\frac{x s-1}{x s}\right)^{s} \quad \forall x \in[1,2, \ldots, L] .
$$

The impact of $Y$ on firms' revenues depends on the sign of $(2-s)$. Total output plays a twofold role in firms' decisions. On the one hand, a higher $Y$ implies a stronger demand for the intermediate good $\left(p\left(Q_{x}\right)\right.$ increases), and this raises firms' revenues. On the other hand, the opportunity cost of employment $\alpha \cdot Y$ goes up, discouraging hirings and decreasing revenues. If $s>2$, competition among the sectors is sufficiently tough to eliminate the positive demand effect and total output worsens firms' revenues.

\subsection{Zero-profit condition}

Entering a market is a costly activity that requires time. Each firm deciding to compete in a sector with $x$ incumbents must pay a flow cost $\frac{h}{x+1}$ until it enters the market $^{16}$. The assumption of a cost decreasing in the level of competition may be interpreted in the sense that barriers to entry are more costly to break up in presence of a monopoly than in a very competitive sector. This seems a reasonable condition and it is in line with the conclusions of some research on endogenous entry deterrence ${ }^{17}$.

Decreasing entry costs also allow to have a finite measure of potential entrants whatever the number of incumbents. If the expected cost of entering a market was the same for any $x$, firms would only try to produce in sectors with no competition, $x=0$, because they ensure the highest expected profits.

\footnotetext{
${ }^{16}$ This way of structuring firms' entry is the same used in a textbook matching framework to model the posting of a job vacancy (see Pissarides, 2000).

${ }^{17}$ Waldman (1991), for instance, argues that the presence of many incumbents makes it easier for some of them to freely benefit from the other firms' investment in entry deterrence. As in all free-rider problems, underinvestment may result, easing potential entrants' task. Of course this problem is more likely to occur with many incumbents.
} 
The expected utility of a firm willing to enter a market with $x$ competitors is:

$$
\begin{aligned}
r J_{V}(x)= & -\frac{h}{x+1}+q\left[J_{E}(x+1)-J_{V}(x)\right]+\left[m_{x}-q\right]\left[J_{V}(x+1)-J_{V}(x)\right] \\
& +\delta \cdot x\left[J_{V}(x-1)-J_{V}(x)\right], \quad \text { with } x \in[0,1, \ldots, L-1] .
\end{aligned}
$$

To find $V_{x}$, the number of potential entrants with $x$ competitors, I impose that each firm enters the market as long as the expected return is nonnegative:

$$
r J_{V}(x)=0 \quad \forall x \in[0,1, \ldots, L-1]
$$

Using (10), (14), (15), and (16) one gets:

$$
\begin{cases}\frac{m_{x}}{x+1}=\frac{q}{h} \frac{(1-\beta)}{x s-1} \alpha^{1-s} \cdot Y^{2-s}\left(\frac{x s-1}{x s}\right)^{s}-r & \forall x \in[2, \ldots, L] . \\ \frac{m_{x}}{x+1}=\frac{q}{h} \frac{(1-\beta)}{x s-1} \alpha^{1-s} \cdot Y^{2-s}\left(\frac{x s-1}{x s}\right)^{s}-(r+\delta) & \text { for } x=1 .\end{cases}
$$

Two points are worth stressing. First, differently from a standard search and matching framework, in this model there are no congestion effects, because each firm faces a constant entry rate, $q$, that is not affected by the number of potential entrants. In fact, a high value for $m_{x}=q \cdot V_{x}$ has a negative impact not on the entrants but on the incumbents, since it raises the arrival rate of a new competitor ${ }^{18}$.

Second, the rate $m_{x}$ is positive as long as the RHS of (17) is positive. In Appendix A I show that there exists a finite number $L$ such that $m_{L}=0$ and $m_{x}$ is positive for any $x \in[1, \ldots, L-1] .{ }^{19}$ In economic terms, this means that at $x=L$, an incumbent can recoup the cost he paid to enter the market only if competition does not increase even more in the future or, equivalently, that no firm will enter a sector in which there are already $L$ competitors.

\footnotetext{
${ }^{18}$ For instance, if there are too many entrants at $x=1$, the monopolist' expected revenues are not high enough to repay the entry costs, and the expected discounted value $r J_{E}(1)$ is negative. In turn, this implies that $r J_{E}(2)$ is also negative, so no additional firm will enter a market with $x=1$. This also explains why I need to impose $m_{0}$ exogenous: at $x=0$ there are no incumbents and the zero-profit condition does not apply.

${ }^{19}$ More correctly, $L$ is an integer number such that the RHS of (17) is strictly positive when evaluated at $L-1$ and nonpositive at $x=L$. For simplicity reasons, I neglect this integer constraint. I take it into account only in the numerical analysis.
} 


\section{Existence and Uniqueness of the Equilibrium}

Definition A steady-state general equilibrium is defined as a vector $\left[l_{x}, w_{x}, V_{x}, p\left(Q_{x}\right)\right] \forall x \in[1,2, \ldots, L]$, a probability distribution $\left[\pi_{0}, \pi_{1}, \pi_{2}, \ldots, \pi_{L}\right]$, and a value $Y$ of the final good satisfying: (i) The F.O.C.s (13) of the bargaining problem; (ii) the Nash equilibria (12) of the Cournot games; (iii) the zero profit conditions (17); (iv) the steady-state distribution (4); (v) the F.O.C. in the final good sector (2).

In Appendix B I show that these five conditions can be rearranged so to have expressions that contain only two endogenous variables, $Y$ and $L$. Therefore, the equilibrium of the model can be characterized by a system of two equations in $(L, Y)$ space:

$$
\left\{\begin{array}{l}
\mathbb{Z} \mathbb{P}(Y, L) \equiv Y^{2-s}-\frac{r \cdot h}{q} \frac{L s}{1-\beta} \cdot\left[\alpha \frac{L s}{L s-1}\right]^{s-1}=0 \\
\mathbb{C E}(Y, L) \equiv Y-\left[I \cdot \alpha^{1-s} \cdot \sum_{x=1}^{L}\left(\frac{x s-1}{x s}\right)^{s-1} \pi_{x}\right]^{\frac{1}{s-1}}=0
\end{array}\right.
$$

The first equation is obtained by evaluating both (12) and the zero profit condition (17) at $x=L$. It is henceforth denoted as the implicit function $\mathbb{Z P}(Y, L)=0$. The second equation of the system (18) is obtained by inserting the Cournot equilibrium condition (12) in the final good function and is henceforth denoted as the implicit function $\mathbb{C E}(Y, L)=0$. If a solution to this system exists, then the equilibrium values of $Y$ and $L$ uniquely determine the wage $w_{x}$, the level of employment $l_{x} \cdot x$, the number of potential entrants $V_{x}$, and the steady state distribution.

Proposition 1 If $s \geq 2$, the system (18) has a unique positive solution in the space $(L, Y)$. If $1<s<2$, the system admits at least two solution in the space $(L, Y)$, one at the origin.

The formal proof is in Appendix B. Still, some intuition may be grasped by inspecting the shape of the two equations of (18) in the space $(L, Y)$ (see Figure 2).

Equation $\mathbb{C E}=0$ is always increasing in the $(L, Y)$ space, since tougher competition entails a greater amount of intermediate goods produced and sold in the economy and thereby an increase in the production of total output. 


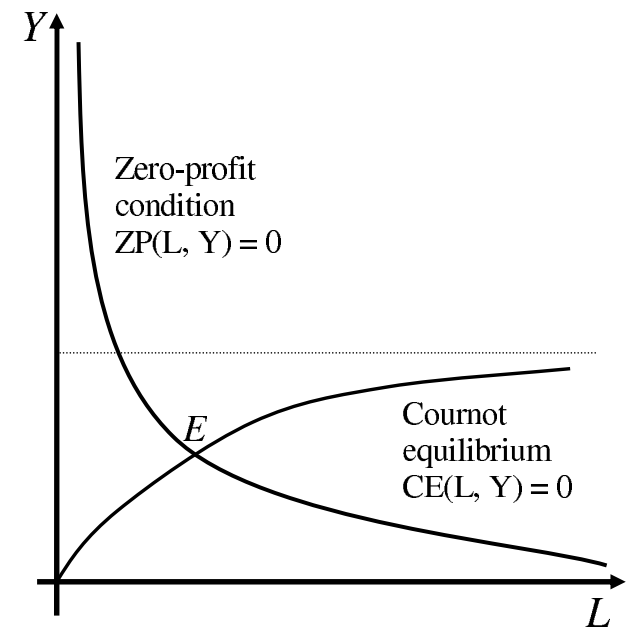

(a)

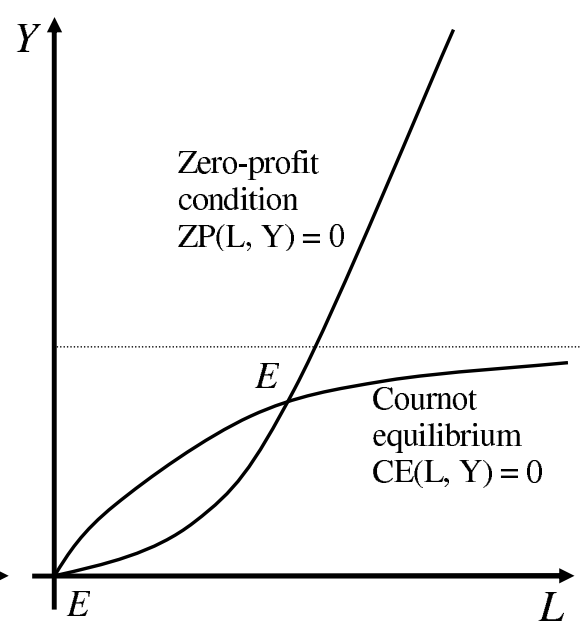

( b )

Figure 2: (a) Equilibrium as $s>2$. (b) Equilibria as $1<s<2$.

If $s>2$ (resp. $1<s<2$ ) equation $\mathbb{Z P}=0$ describes a decreasing (resp. increasing) relationship between $Y$ and $L .^{20}$ The elasticity of the demand for the intermediate goods determines the shape of the zero profit condition. The reason rests on the two competing effects that total output has on firms' revenues: the positive demand effect and the negative opportunity cost of employment effect. As $s>2$, firms' revenues are decreasing with $Y$, because a higher opportunity cost of employment drives real wages up and reduces the demand for labour. The smaller the revenues, the lower is the number of firms that is sufficient to make entry no longer profitable, so $Y$ has a negative impact on $L$. On the contrary, as $1<s<2$, competition among the sectors is so low that the positive impact of a higher $Y$ on the demand outweighs its negative effect on the wage bill. Firms' revenues are increasing in the level of total output; a greater $Y$ requires a tougher level of competition (i.e. a higher $L$ ) to soak up all the advantages of entry.

The quantitative results of Section 6.4 show that the most important conclusions of the model hold true in both scenarios.

\footnotetext{
${ }^{20}$ The case $s=2$ is explored in Appendix B.
} 


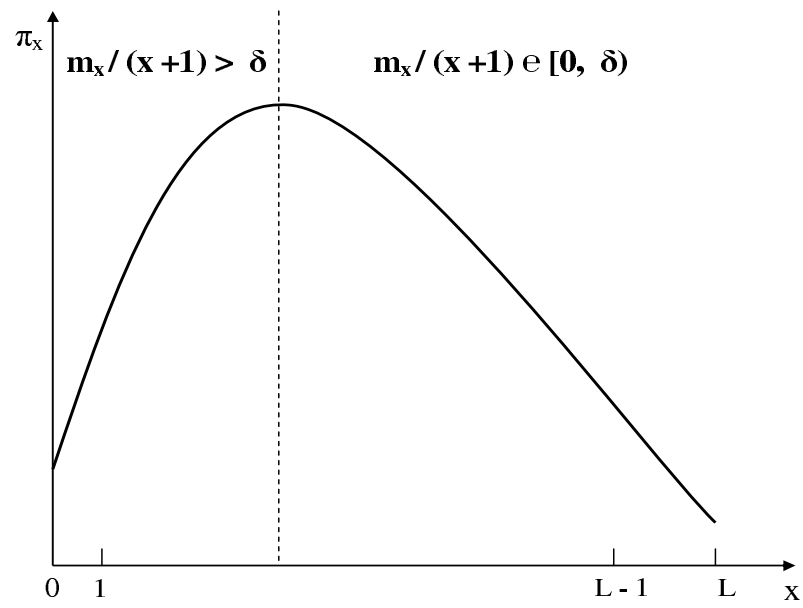

Figure 3: The endogenous distribution has an hump-shaped form.

\subsection{Properties of the Distribution}

Corollary 1 If $m_{0}>\delta$, the steady-state distribution $\left[\pi_{0}, \pi_{1}, \pi_{2}, \ldots, \pi_{L}\right]$ is humpshaped.

The proof is in Appendix C. Intuitively, the stochastic process described in section 2.2 is regulated by firms creation - that is stronger the higher $m_{x}$ is - and firms destruction, governed by the rate $\delta \cdot(x+1)$. When competition is scarce ( $x$ very low) the creation rate outnumbers the destruction rate, because many firms are eager to enter the sector and gain huge profits, raising $m_{x}$. In this case $\pi_{x+1}>\pi_{x}$. As competition gets tougher, the eagerness of potential entrants peters out, the destruction rate $\delta \cdot(x+1)$ predominates, and $\pi_{x+1}<\pi_{x}$. It may be the case that $\delta$ is set so high that the endogenous rates $m_{x}$ are lower for any given $x$. Then, from equation (3), $m_{0}>\delta$ implies that $\pi_{1}>\pi_{0}$ and the distribution reaches the maximum at $x=1$.

\section{Deregulation in Products and Labour Markets}

In this section I summarize the effects of product and labour market deregulation on employment and the real wage. I also present some inequality results. I consider the parameter $h$, the flow cost of entry, as a proxy for the extent of the rigidity in the product market, and the bargaining power of the unions of workers $\beta$ as an indicator 
of the level of regulation present in the labour market. Formally, I totally differentiate the system (18) and apply the implicit function theorem. Computations are presented in Appendix D.

\subsection{Employment and Real Wage Effects}

Proposition 2 Decreasing the flow cost of entry in the product market, $h$, or the bargaining power of workers' unions, $\beta$, raises the aggregate level of employment $E$. The effects on the real wage are ambiguous.

Employment effects

Lowering the flow cost of entry $h$ or the bargaining power $\beta$ makes more firms willing to enter the market for each level of competition $x$. This in turn raises the rates $m_{x}$ at which incumbents increase in any sector (notice from equation (17) that, conditional on $Y$, the rate $m_{x}$ decreases with $\beta$ and $\left.h\right)$. The maximum number of firms $L$ that may compete in each market also goes up, because a lower $h$ (respectively $\beta$ ) decreases the expected cost of entry (resp. raises the expected profits). The distribution $\left[\pi_{0}, \pi_{1}, \ldots, \pi_{L}\right]$ shifts to the right: it is more likely to be employed in competitive sectors. From equation $\mathbb{C E}=0$, a higher $L$ raises the amount of the final good $Y$ produced in the economy: fiercer competition in the intermediate sectors augments the supply of these goods to the final representative firm.

Two countervailing effects intervene on the aggregate level of employment, $E$. On the one hand, a higher $Y$ has a negative effect on the sectoral level of employment $l_{x} \cdot x$ (see equation 12 ), for the opportunity cost of employment goes up. This tends to reduce the aggregate level of employment as $h$ or $\beta$ go down. On the other hand, in the economy there are more sectors with stronger competition. Employment in each intermediate sector increases with competition (notice from equation 12 that $l_{x} \cdot x$ is increasing in $x$ ), so this distribution effect tends to raise $E$. Computations in Appendix $\mathrm{D}$ show that the distribution effect is stronger and the aggregate level of employment goes up.

\section{Real Wage Effects}

As shown in equation (13), the real wage is affected by a change in the entry cost only via $Y$. A reduction in $h$ raises the real wage for any level of $x$ because it increases the amount of the final good going to the employees. However, this does not imply 
that the average real wage, $\bar{w}_{x} \equiv \sum_{x=1}^{L} w_{x} x l_{x} \pi_{x} I$, necessarily increases. The reason is that there is also a distribution effect going in the opposite direction. A reduction in entry costs augments the likelihood of being employed in more competitive sectors, where workers are paid less. It is impossible to say at the analytical level which effect predominates.

This ambiguity is even more noticeable in case of a change in the unions' bargaining power. As an inspection of equation (13) makes clear, a decrease in $\beta$ has a twofold effect on $w_{x}$ : lowering the share of the rents going to the employees exerts a downward pressure, but it also raises the total amount of the final good produced in the economy, so that the wage tends to appreciate in real terms. The net effect cannot be ascertained at the analytical level.

\subsection{Distributive Effects}

Proposition 3 Decreasing the flow cost of entry in the product market, $h$, raises the ratio between the highest and the lowest wage paid in the economy, $w_{1} / w_{L}$.

A first assessment of the effects of product and labour market deregulation on the wage distribution may be carried out by examining the $w_{1} / w_{L}$ ratio. From equation (13), it is equal to:

$$
\frac{w_{1}}{w_{L}}=\frac{s-1+\beta}{s-1} \cdot \frac{L \cdot s-1}{\beta+L \cdot s-1}
$$

This expression is increasing in $L$. The higher is the maximum number of firms that can compete in a market, the wider the dispersion measured by this indicator. Since a decrease in the entry costs $h$ raises $L$, product market deregulation enlarges the gap between the highest paid workers and the lowest paid ones. When entry costs are high, only sectors with a low level competition can survive, because firms need huge profits to repay them. So, deregulation in goods markets allows the existence of markets with fiercer competition, small profits, and low-paid jobs.

On the contrary, the consequences of a weakening of trade unions' power cannot be ascertained at the analytical level. A decrease in $\beta$ has a twofold effect on the ratio $w_{1} / w_{L}$. The direct one - obtained by differentiating the ratio with $L$ fixed - is negative, because a reduction in unions' bargaining power has a stronger negative impact on the wage earned by an employee in a monopoly compared to that earned by a worker in a 
sector with $L$ firms. So a lower $\beta$ reduces the wage dispersion. However, a reduction in $\beta$ also enhances $L$, that in turn raises $w_{1} / w_{L}$. The complexity of the computations do not permit to verify which effect outnumbers the other.

The ratio $w_{1} / w_{L}$ is only one possible measure of wage dispersion. For a fuller account of the distributive effects of product and labour market deregulation, it is necessary to evaluate the effects of a change in $\beta$ and $h$ on the whole distribution $\left[\pi_{0}, \pi_{1}, \ldots, \pi_{L}\right]$. Yet, the computations are too cumbersome to be discerned at the analytical level, so most of the results of the paper are obtained via numerical simulations and will be presented in section 6 .

\subsection{A Caveat}

The comparative statics results summarized in this section are obtained under the hypothesis that $s>2$ or, in case $1<s<2$, that $\left.\frac{d Y}{d L}\right|_{\mathbb{Z P}=0}>\left.\frac{d Y}{d L}\right|_{\mathbb{C E}=0}$ at the equilibrium. These are respectively the examples of Figure 2 (a) and Figure 2 (b) at the point $E^{\prime}$. In the second case, the positive effect on $Y$ of an increase in $L$ is greater on the supply side (the zero profit condition $\mathbb{Z P}=0$ ) than on the demand side (the Cournot equilibrium condition $\mathbb{C E}=0$ ). If this were not the case, an higher $h$ or $\beta$ would raise $L$ and $Y$. Each firm would react to higher entry costs by producing more, knowing that such an increase - experienced in any sector - would raise the amount of the final good $Y$, that in turn would raise the demand for each intermediate good. Expected profits would be higher, so to offset the increase in the expected costs of entry. For this mechanism to work, it is necessary that (i) profits positively depend on $Y$ (as it is with $1<s<2$ or by imposing that $z$ is constant), (ii) the increase in total output caused by a higher production of the intermediate goods is high enough. $\left(\left.\frac{d Y}{d L}\right|_{\mathbb{C E}=0}>\left.\frac{d Y}{d L}\right|_{\mathbb{Z P}=0}\right)$. The simulation results that I will present in the next sections show that even with $1<s<2$, this chain of effects does not verify, and the results of the comparative statics are correct.

\section{Calibration}

I take the month as unit of time. Data refer to the period 2002-2003 in Belgium. Table 1 summarizes my calibration procedure. The discount rate is fixed at 0.004 (5\% on an annual basis). 


\begin{tabular}{|c|c|c|}
\hline Variables & Interpretation & Source \\
\hline \hline $\mathrm{s}$ & measure of competition between sectors & u about $8 \%$ \\
\hline$\delta$ & net destruction rate of a business & INS $(2000 ; 2001 ; 2002)$. \\
\hline $\mathrm{N}$ & labour force per sector & imposing full employment at $x=L+1$. \\
\hline$\beta$ & trade unions' bargaining power & imposing $w_{L} / \alpha Y \cong 0.98$. \\
\hline$r$ & discount rate & $5 \%$ on annual basis. \\
\hline$h / q$ & expected cost of entry & zero profit equation $\mathbb{Z P}=0$ \\
\hline$\alpha$ & fraction of $Y$ going to the unemployed & lowest wage close to minimum wage. \\
\hline
\end{tabular}

Table 1. Values of the variables for calibration.

In the theoretical setting, the zero profit condition determines the maximum number that may compete in a sector, $L$ while the expected cost of entry $\frac{h}{(x+1) q}$ is exogenous. The difficulty of finding empirically grounded figures for the entry costs makes easier to invert the procedure in the calibration part: $L$ is fixed as exogenous, whereas $\frac{h}{(x+1) q}$ is determined by the zero profit condition ${ }^{21}$. $L$ is thus set equal to 15 . It may seem a small number. Recall however that firms compete both within each sector - $\grave{a} l a$ Cournot - and among sectors, the intensity of this competition depending on the value of the elasticity $s$. Imposing $L=15$ simply means that in the economy there are at most 15 firms that produce exactly the same type of good, competing with others companies that sell broadly similar items.

The firm's destruction rate $\delta$ is inferred by looking at the number of Belgian firms that lose each year their VAT code number. The Belgian Institute of Statistics provide these data for the years 2000-2001-2002. ${ }^{22}$ The monthly destruction rate is about 0.004 in all the three years ${ }^{23}$. The exogenous rate of entry $m_{0}$ is normalized to 1 . In the model, the labour force in each sector is exogenous and normalized to 1 . In the calibration, I impose that it is equal to the level of employment if $L+1$ firms were producing in the sector; this implies that even when the level of competition is highest

\footnotetext{
${ }^{21}$ For simplicity, I also avoid to pin down the flow cost $h /(x+1)$ and the entry rate $q$ separately.

${ }^{22}$ I rule out all the firms that declared no employees.

${ }^{23}$ The same source also provides the firms' creation rate for the same years. It is about 0.0035 , suggesting that the stock of active firms was fairly stable in that period.
} 
(at $x=L$ ), there is still some frictional level of unemployment. This assumption allows to have the unemployment rate as a function of $s, \delta, m_{0}, L$ only. ${ }^{24}$ Since I have already attributed a value to the last three variables, I can find $s$ by imposing that the unemployment rate should be close to $7 / 8 \%$, the percentage that Belgium experienced in the last five years. The corresponding value of $s$ is 2.1 .

In Belgium, the gross monthly minimum wage is about 1400 euros; for a single employee that works full-time the net salary is about 1100 euros. The unemployment benefits are generous: a single beneficiary may receive a subsidy up to 1144 euros per month. So, to calibrate the bargaining power of workers'unions I impose that the ratio between the lowest wage in the economy and the income of unemployed workers - that, by using equation $(13)$, is $(L \cdot s-1) /(L \cdot s-1+\beta)$ - is close to 1 . With such a ratio equal to $0.98, \beta$ is 0.62 . The number of sectors in the economy is fixed to 2350 . The parameter $\alpha$ is obtained by imposing that $w_{L} \cong 1100$ euros; the resulting value is 0.01 .

Finally, the expected cost of entry $h / q$ is inferred by imposing the zero profit condition $\mathbb{Z P}=0$. The resulting value is 143.79 , a very tiny amount. This is because the construction of the model is such that the expected profits of a firm are small compared to the wages.

\section{Quantitative Results}

\subsection{Wage Distribution}

A first interesting result that stems from the calibration concerns the wage distribution. By pinning down the variables $\delta, m_{0}, s$, and $L$ only on the basis of employment and business data, the resulting wage density function $w_{x} \rightarrow l_{x} \cdot x \cdot \pi_{x} \forall x$ is unimodal and positively skewed, like the earnings distributions observed in the data of most countries (see Figure 4).

Why does the wage density function have such a shape? The unimodal property depends on the structure of the probability distribution $\left[\pi_{0}, \pi_{1}, \ldots, \pi_{L}\right]$, proved in Corollary 1 . The positive skewness property stems from the convexity of the wage function

\footnotetext{
${ }^{24}$ Computations are available on request.
} 

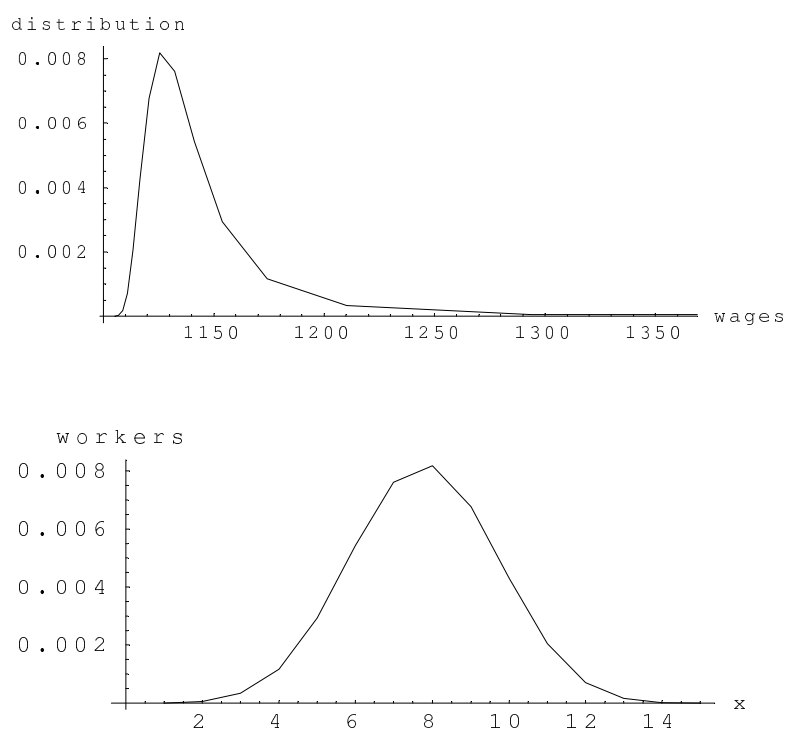

Figure 4: Above: Wage distribution $w_{x} \rightarrow l_{x} \cdot x \cdot \pi_{x}$ for $x \in[1,2, \ldots, L]$. Below: distribution of workers per level of competition $x \rightarrow l_{x} \cdot x \cdot \pi_{x}$ for $x \in[1,2, \ldots, L]$.

(13) with respect to $x .^{25}$ The wage loss caused by an increase in competition is larger the more oligopolistic is the sector. While workers employed in sectors with $L-1$, $L-2, L-3$ competitors earn broadly the same salary, the difference between the wage of the employee of a monopolist and that of duopolist is much wider. So, most of the earnings are concentrated on the left tail of the distribution.

What the model is not able to capture is the large difference in absolute value between the richest and the poorest. The Gini index resulting from the calibration is very low, about 0.009. One obvious explanation is the lack in the model of many features that explain most of the income inequality in industrialized countries, such as rents and revenues coming from the overall wealth of the individuals. An additional reason stems from the wage equation, that is not convex enough in $x$ to display a large difference between the highest wages and the lowest ones.

\footnotetext{
${ }^{25}$ If we ignore the integer problem, this can be easily seen by computing the second derivative of $w_{x}$ with respect to $x$ and noting that is positive.
} 

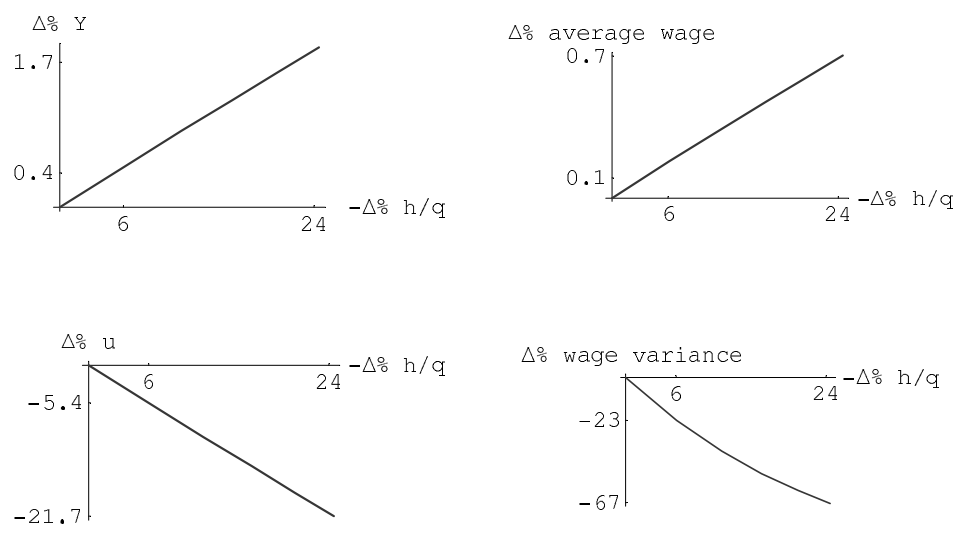

Figure 5: Numerical results: a reduction in the expected entry costs, $h / q$.
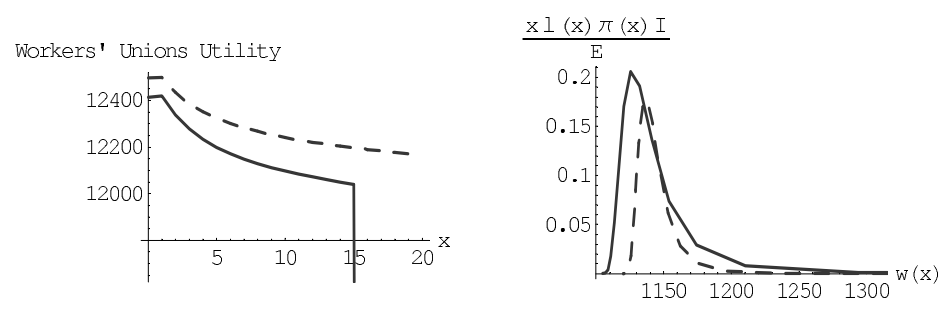

Figure 6: Solid lines: calibration results. Dotted lines: simulation with $h / q 25 \%$ lower.

\subsection{Lowering entry costs}

I consider a reduction up to $25 \%$ in the expected costs of entry in the labour market, $h / q$. Figures 5 and 6 summarize the main results ${ }^{26}$. The maximum number of firms that may compete shifts from 15 to 20 , and the output $Y$ is raised by $1.7 \%$. The unemployment rate decreases up to 1.5 percentage points. The average real wage goes

\footnotetext{
${ }^{26}$ The wage distribution graph in Figure 6 may seem wrong, since the area below one density is larger than the other one. Part of the confusion comes from the fact that these are discrete distributions. Consider the following example: Distribution 1: $((1100,0.1),(1200,0.5),(1300,0.4)$. Distribution 2: $((1200,0.3),(1250,0.4),(1300,0.3)$. The average wage is greater in Distribution 2 than in Distribution 1. But if I draw the two densities by connecting the points with a solid line, distribution 2 is always entirely below distribution 1 .
} 
up, but very slightly: the salary gain is about 8 euros, that corresponds to a $0.7 \%$ increase. Such a tiny improvement depends on the two potentially offsetting effects mentioned in section 4.1, the positive income effect and the negative distribution effect. The small increase in $\bar{w}_{x}$ means that the former slightly outnumbers the latter.

\section{Inequality}

Lower entry costs also affect the steady state distributions. The consequences in terms of wage inequality are mixed. On the one hand, we know from section 4.2 that the ratio between the highest and the lowest wage, $w_{1} / w_{L}$, increases. However, the numerical results show that diminishing $h / q$ lowers the wage variance and the Gini index ${ }^{27}$. The decline in the variance is considerable: once $h / q$ is reduced by $25 \%$, it plummets from 297.3 to 96.3 euros, about $68 \%$ lower. The Gini index also shrinks by about $39 \%$.

How can such different results be explained? Tougher competition in the product market lowers the variance and the Gini index because there are now more workers employed in sectors with many firms, that implies more employees earning the same wage. So, the fact that the distance between the highest and the lowest wage paid in the economy widens does not entail an overall increase in wage inequality.

\section{Welfare of trade unions}

Decreasing the entry costs also has non trivial effects on the expected utility of a worker's union, $r U_{W}(x)$. Again, the presence of a negative distribution effect may offset the wage and employment gains obtained by a more competitive product market. This can be easily grasped by inspecting equation (6). A decrease in $h / q$ raises the instantaneous utility of the union, equal to $w_{x} x l_{x}+\left(1-x l_{x}\right) \alpha Y$, because $w_{x}$ and $Y$ go up. However, the rate $m_{x}$ at which a new firm enters the market increases as well, making the union more likely to operate in a more competitive market, with lower rents to be shared.

As far as the change in $h / q$ is concerned, the benefits caused by the increase in unions' instantaneous utility prevail. A decrease in entry costs make workers' unions better off for any level of competition. Even unions in which all the members are are unemployed (operating in sectors with $x=0$ ) benefit from the reduction in $h / q$,

\footnotetext{
${ }^{27}$ The Gini index is computed by taking the income of the unemployed into account
} 

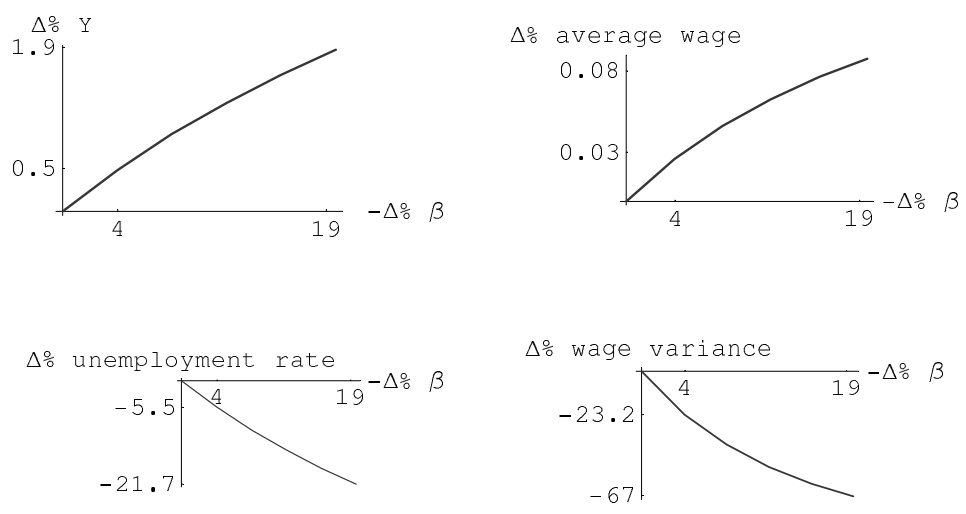

Figure 7: Numerical results: a reduction in the bargaining power of workers' unions, $\beta$.
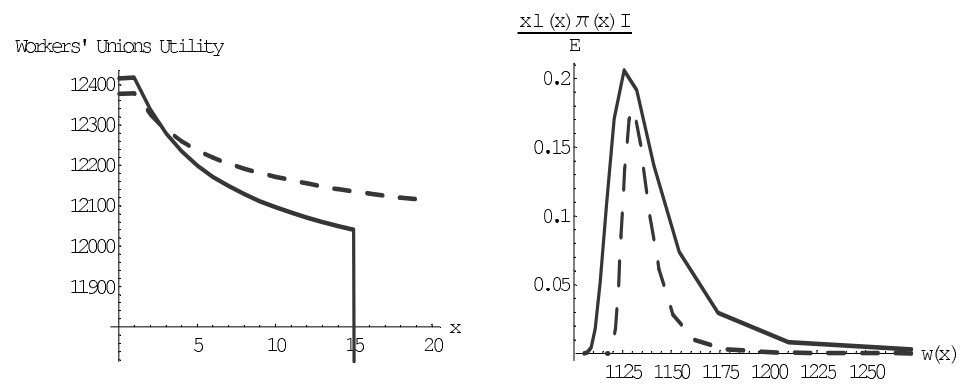

Figure 8: Solid lines: calibration results. Dotted lines: simulation with $\beta 20 \%$ lower.

because the income of the unemployed, $\alpha Y$, is higher.

\subsection{Lowering workers' unions bargaining power}

I consider a reduction up to $20 \%$ in $\beta$. As far as the unemployment and the total output are concerned, squeezing $\beta$ has the same effects of a reduction in $h / q$. Figure 7 shows the evolution of $Y$ and $u$ as $\beta$ decreases. Even the orders of magnitude appear broadly similar: a reduction up to $20 \%$ of unions' bargaining power shrinks unemployment as much as a decrease by $25 \%$ in entry costs. The effects on the average real wage are almost negligible: diminishing $\beta$ by $20 \%$ raises $\bar{w}$ by 1 euro, that corresponds to a $0.08 \%$ increase. This is due to the fact that, besides the positive income and the negative distribution effect present in the case of lower entry costs, a change in $\beta$ also 
affects the wage equation; from (13), a lower $\beta$ decreases the $w_{x}$ for any value of $x$. The two negative effects basically offset the income effect caused by a lower $\beta$.

\section{Inequality}

A lower unions' bargaining power squeezes the wage variance and the Gini index. A $20 \%$ reduction of $\beta$ translates into a decrease in the wage variance of about $68 \%$; the size of the decline is identical to that caused by the $25 \%$ decrease in entry cost. The Gini index is also lowered by $50 \%$. The explanations for such a sharp decline are the same expressed for the case of product marker deregulation. A lower workers' unions bargaining power triggers competition that in turn entails a larger share of workers having the same salary.

Welfare of trade unions

The effects of a reduction in $\beta$ on the welfare of workers' unions depend on the level of competition in the intermediate sector. The first graph of Figure 8 illustrates that; trade unions operating in a monopoly and in duopoly are worse off after the reduction in $\beta$, whereas those belonging to sectors with more than one competitor and the unemployed are better off. Consider equation (6). As in the case of lower entry costs, two countervailing forces affect unions' expected utility. On the one hand, a lower $\beta$ raises the instantaneous utility of the union, $w_{x} x l_{x}+\left(1-x l_{x}\right) \alpha Y$, because both $Y$ and $w_{x}$ are higher. On the other hand, the capital loss due to the increase in competition augments because of the higher probability a new firm will enter the market. Because firms' profits are decreasing and convex with respect to $x$, this second effect is stronger in sectors with low competition. Labour market deregulation worsens the welfare of trade unions in poorly competitive industries, even though both the aggregate real wage and the level of employment go up.

\subsection{Robustness Analysis}

A robustness exercise is conducted on parameters $\beta$ and $s$ that, by determining the share of employers' rents and the level of competition among sectors, influence most the entry behaviour of the firms. Table 2 illustrates the results. The main conclusions of the model hold true for reasonable changes in the parameters. In addition, notice that the employment gains obtained via a reduction in $h / q$ are larger the lower is the value of $\beta$. Deregulation in product markets has a better performance in less regulated 


\begin{tabular}{|c|c|c|c|}
\hline $25 \%$ decrease in $h / q$ & $\Delta u / u$ & $\Delta \bar{w} / \bar{w}$ & $\Delta$ variance / variance \\
\hline Baseline & $-20 \%$ & $+0.7 \%$ & $-68 \%$ \\
\hline$s \in(1.2,5)$ & $-[10,32] \%$ & $+[0.2,1.7] \%$ & $-[61,68] \%$ \\
\hline$\beta \in(0.2,0.9)$ & $-[10,40] \%$ & $+[0.5,2.5] \%$ & $-[60,70] \%$ \\
\hline$s \cong 5$ & $-8 \%$ & $+0.2 \%$ & $-70 \%$ \\
\hline$\beta \cong 0.2$ & $-40 \%$ & $+3 \%$ & $-78 \%$ \\
\hline \hline $20 \%$ decrease in $\beta$ & $\Delta u / u$ & $\Delta \bar{w} / \bar{w}$ & $\Delta$ variance / variance \\
\hline Baseline & $-20 \%$ & $+0.08 \%$ & $-68 \%$ \\
\hline$s \in[1.2,5)$ & $-[15,20] \%$ & $+0.1 \%$ & $-[40,75] \%$ \\
\hline$\beta \in[0.3,0.9)$ & $-[13,20] \%$ & $+[0.1,0.2] \%$ & $-[35,68] \%$ \\
\hline$s \cong 5$ & $-20 \%$ & $+0.2 \%$ & $-97 \%$ \\
\hline$\beta \cong 0.2$ & $-12 \%$ & $+0.3 \%$ & $-35 \%$ \\
\hline
\end{tabular}

Table 2. Sensitivity analysis

labour markets, in contrast with the empirical results of Griffith et al. (2007) and Fiori et al. (2008) that find a positive relationship between the magnitude of the increases in employment due to interventions in the product market and the workers' bargaining power. On the other hand, the higher $\beta$, the more effective is its reduction in terms of employment and output gains.

Another interesting result concerns the welfare of trade unions. As $s>5$, all unions benefit from labour market deregulation, differently from the baseline model. From equation (14), the differences in firms' revenues caused by a change in $x$ are decreasing in $s$. The losses firms incur when one more competitor enters the market are less acute as competition between sectors gets tougher. So with high values of $s$ even unions in poorly competitive sectors value more the positive instantaneous utility effect caused by a reduction in $\beta$ than its negative capital loss effect.

\section{Extensions: Modifying Unions' Utility}

In the model the wage negotiation takes place at sectoral level between unions that maximize the sum of the incomes of its members (the so-called "rent maximand"), that make up $100 \%$ of the workforce. In this section I wonder how the welfare and 
inequality results obtained in the paper change by relaxing these assumptions.

The rent maximand hypothesis has been criticized for it implies that unions place more weight on wage changes and less on employment changes than the results of the empirical literature suggest (for instance Carruth and Oswald, 1985). To gauge the extent of such a bias, I compute the logarithmic marginal rate of substitution between wages and employment, defined as $\epsilon \equiv-\frac{l_{x}}{w_{x}} \frac{d w_{x}}{d l_{x}}$. The higher it is, the greater the favour towards employment changes compared to wage changes. In the present model, $\epsilon=1-\frac{\alpha Y}{\bar{w}_{x}}$. At the calibration level, the average value of such elasticity is 0.04 , against a range of $0.1-0.3$ deemed empirically consistent by Clark and Oswald (1993). So, to put more weight towards employment, two solutions are thinkable: (i) introducing risk aversion in unions' preferences, (ii) reducing the calibrated value of $\frac{\alpha Y}{w_{x}}$. Unfortunately, using a more general utility function, such as $\frac{w_{x}^{\delta}}{\delta} l_{x}+\frac{(\alpha Y)^{\delta}}{\delta}\left(1-l_{x}\right)$ studied by Clark and Oswald (in which $\delta$ measures one minus the degree of relative risk aversion), makes the model analytically intractable. ${ }^{28}$ Thus I look if the welfare results of the model are robust to higher values of the marginal rate of substitution between wage and employment by increasing the calibrated value of $\epsilon$. Simulation results show that a reduction in $\beta$ makes unions in sectors with $x=1$ and $x=2$ worse off as long as $\epsilon \leq 0.15$. For $0.15<\epsilon<0.3$, unions are always better off. Still, these results must be taken with caution: for an average $\epsilon$ equal to $0.3, \bar{w}_{x} / \alpha Y$ must be 1.43 . Such a wide gap between the average wage and the opportunity cost of employment can be obtained only via unrealistically high values for worker's bargaining power and the unemployment rate (respectively, 0.9 and 0.2 ).

In the second extension, I water down the $100 \%$ union density condition and impose that in $\gamma \cdot I$ sectors $(0<\gamma<1)$ workers are not unionized. The simplest way to add this feature into the model is by setting $\beta=0$ for these sectors. Thus, the wage of non-unionized employees is equal to the opportunity cost of employment, $\alpha \cdot Y$. In non-unionized sectors, firms hire more and get higher revenues for any level of $x$, so the number of incumbents above which entry becomes unprofitable is larger in unionized sectors. Since in the model unions intervene only in the wage negotiation, I choose $\gamma$ to

\footnotetext{
${ }^{28}$ Since the F.O.C. of the bargaining problem is no longer log-linear in $w_{x}$, the resulting wage curve becomes a second-order non-linear difference equation.
} 


\begin{tabular}{|c|c|c|c|}
\hline $25 \%$ decrease in $h / q$ & $\Delta u / u$ & $\Delta \bar{w} / \bar{w}$ & $\Delta$ variance / variance \\
\hline Unionized + Non-unionized & $-16 \%$ & $+0.1 \%$ & $-57 \%$ \\
\hline National Unions & $-44 \%$ & $+0.1 \%$ & $-54 \%$ \\
\hline Insider vs. Outsider & $-21 \%$ & $+0.7 \%$ & $-67 \%$ \\
\hline \hline $20 \%$ decrease in $\beta$ & $\Delta u / u$ & $\Delta \bar{w} / \bar{w}$ & $\Delta$ variance / variance \\
\hline Unionized + Non-unionized & $-15 \%$ & $+0.06 \%$ & $-68 \%$ \\
\hline National Unions & $-32 \%$ & $+0.07 \%$ & $-49 \%$ \\
\hline Insider vs. Outsider & $-21 \%$ & $+0.08 \%$ & $-67 \%$ \\
\hline
\end{tabular}

Table 3. Impact of lower $h / q$ and $\beta$ under three different scenarios.

match not the level of union density but an indicator of union bargaining coverage in Continental Europe. Following Delacroix (2006), $\gamma=0.2$. The calibration procedure follows closely the one of section 5 and delivers a union wage premium of $4 \%$, at the lower bound of the range (4 - $10 \%$ ) found by Blanchflower and Freeman (1992) for some OECD countries. The second and the sixth line of Table 3 summarize the main results. As expected, a reduction in $\beta$ appears less effective than in the benchmark case, for it involves only a fraction $1-\gamma$ of the sectors in the economy.

It is also worth seeing if the negative effect that a reduction in $\beta$ causes on the welfare of some unions holds true if they operated not at sectoral but at national level. I then consider a third extension to the model, in which two national unions, one representing all the firms the other all the workers, negotiate the wage level, that will be therefore the same for any worker in the economy. The bargaining problem in (8) becomes:

$\max _{w}\left[\sum_{x=1}^{L} w \cdot x \cdot l_{x} \pi_{x} I+\alpha Y \sum_{x=0}^{L} 1-x l_{x} \pi_{x} I-\bar{U}_{W}\right]^{\beta}\left[\sum_{x=1}^{L}\left(p\left(Q_{x}\right)-w\right) \cdot x \cdot l_{x} \pi_{x} I-\bar{U}_{F}\right]^{1-\beta}$

with $U_{W}=\alpha Y \cdot I$ and $U_{F}=0$. Solving the maximization problem one easily gets the wage equation. For the rest, the model is identical to the benchmark one (details are available on request), the only difference being that the level of employment chosen by a single firm in a generic sector no longer affects $w$, that depends only on the aggregate levels of employment and revenues. The bottom line of this extension is that workers' unions always benefit from labour market deregulation. Since they care only about 
aggregate variables, they are no longer worried about the change in competition that may occur in one specific sector of the economy. Previous literature (Calmfors and Driffil, 1988; Alesina and Perotti, 1997) stressed the positive role played by national unions in taming inflation, for they internalize the negative impact of their wage demands on prices. Similarly, this paper suggests that national unions are more prone to embrace apparently inexpedient reforms because they realize their positive impact on aggregate employment and real wages.

Finally, in the last extension I introduce an insider-outsider logic into the labour market. I impose that only employed workers belong to a union, so that the welfare of the unemployed does not appear in union's utility function. The Bellman equation (6) and the threat point are modified accordingly; yet, it is easy to check that the wage equation (13) does not change. As in the previous scenario, a decrease in $\beta$ raises unions' welfare irrespective of the level of competition in the sectors they belong to. This because in this setting the employment gains of a policy are valued more by unions than in the benchmark case. While in the baseline model union density is fixed at $100 \%$, here an increase in employment automatically broadens unions' membership, raising their welfare.

\section{Conclusion}

In Europe, reforms aimed to improve the functioning of the product and labour markets are at the centre of the political agenda. This paper does not argue that such changes must not be undertaken; rather, that the overall consequences for the economy are more mixed than an analysis uniquely focused on the employment and wage gains suggests. This can help to understand the negative reactions the introduction of these reforms often stirs.

Easing the cost for a firms to enter the market reduces the wage variance and the Gini index but enlarges the distance between the lowest and the highest pay in the economy. Labour market deregulation worsens the welfare of workers employed in markets with low competition, while it raises the utility of all the others.

The paper also offers some arguments in favour of the centralization of the wage setting process, for unions operating at sectoral level do not internalize the aggregate positive effects of some policies. This would leave room for some political economy 
reflections that can be left for future research.

\section{Acknowledgements}

I am indebted to Fabien Postel-Vinay for several insightful and helpful conversations. I thank the editor and one anonymous referee for many useful comments. I also benefited from discussions with Aleksander Berentsen, Etienne Lehmann, Amina Mahdi, Henri Sneessens, John Sutton, Mirco Tonin, Bruno Van der Linden, and the participants to the DMMG conference in the University of Algarve, the IZA workshop on Matching Frictions in Bonn, the EALE conference in Amsterdam, and the "Brucchi Luchino" workshop in Rome. A grant of the Belgian National Bank is gratefully acknowledged. The usual disclaimer applies.

\section{Appendix A. Existence of $\mathbf{L}$}

I wonder if there exists a finite number $L$ such that $m_{L}=0$. Three conditions are sufficient for the existence of $L$. First, the term in the RHS of (17) is decreasing in $x$. Second, that it tends to a positive value as $x=1$. Third, that it tends to a negative value as $x \rightarrow+\infty$. If these conditions are fulfilled, there exists only one $x=L$ such that $m_{L}=0$ (and the RHS of (17) is equal to zero).

Ignoring for simplicity the integer problem, the derivative of the first term in the RHS of (17) with respect to $x$ is:

$$
\frac{q}{h}(1-\beta) \alpha \cdot Y\left[\frac{d l_{x}}{d x} \cdot \frac{x}{x s-1}-\frac{l_{x}}{(x s-1)^{2}}\right],
$$

that is negative if $d l_{x} / d x$ is negative. This is the case in a Cournot model in which the amount of the good produced by each player decreases with the number of competitors. This can also be checked by differentiating (12).

Substituting $\mathbb{C E}=0$ in the RHS of (17), one gets that a sufficient condition for $m_{1}$ to be positive is

$$
\frac{q}{h} \frac{1-\beta}{s-1} \alpha^{\frac{s^{2}-s-1}{1-s}} \cdot I^{\frac{2-s}{s-1}}\left(\frac{s-1}{s}\right)^{s}>(r+\delta)
$$

Furthermore, $\lim _{x \rightarrow+\infty} \frac{q}{h}(1-\beta) \alpha \cdot Y \frac{l_{x} \cdot x}{x s-1}-r=-r$ because in case of perfect competition (i.e. $x \rightarrow+\infty$ ), both $Y$ and $Q_{x}=l_{x} \cdot x$ take positive finite values. 


\section{Appendix B. Existence of the Equilibrium}

\section{Derivation of system (18)}

Equation $\mathbb{Z P}(L, Y)=0$ is obtained by evaluating both (12) and (17) at $x=L$ and rearranging. Then, substituting $\mathbb{Z} \mathbb{P}(L, Y)=0$ in (17), one gets an expression for $m_{x}$ that depends only on one endogenous variable, $L$ :

$$
\begin{cases}\frac{m_{x}}{r \cdot(x+1)}=\left[\frac{L}{x}\right]^{s} \cdot\left[\frac{L \cdot s-1}{x \cdot s-1}\right]^{1-s}-1, & \forall x \in[2, \ldots, L] . \\ \frac{m_{x}}{(x+1)}=r\left[\frac{L}{x}\right]^{s} \cdot\left[\frac{L \cdot s-1}{x \cdot s-1}\right]^{1-s}-(r+\delta), & \text { for } x=1\end{cases}
$$

Notice that $m_{x}$ is increasing in $L{ }^{29}$

Equation $\mathbb{C E}(L, Y)=0$ is obtained by applying the law of large numbers and using (12):

$$
\begin{aligned}
Y & =\left[\sum_{i=1}^{I} Q_{i}^{\frac{s-1}{s}}\right]^{\frac{s}{s-1}}=\left[I \pi_{1} Q_{1}^{\frac{s-1}{s}}+\ldots+I \pi_{x} Q_{x}^{\frac{s-1}{s}}+\ldots+I \pi_{L} Q_{L}^{\frac{s-1}{s}}\right]^{\frac{s}{s-1}}= \\
& =I^{\frac{s}{s-1}} \cdot\left[\sum_{x=1}^{L} Q_{x^{\frac{s-1}{s}}} \pi_{x}\right]^{\frac{s}{s-1}}=\left[I \cdot \alpha^{1-s} \cdot \sum_{x=1}^{L}\left(\frac{x s-1}{x s}\right)^{s-1} \pi_{x}\right]^{\frac{1}{s-1}} .
\end{aligned}
$$

Notice that the F.O.C.s (13) and the solutions of the Cournot game (12) are expressed as a function of $Y$ only. The zero profits conditions (B.1) determine the values of $V_{x}$ as a function of $L$. Thus, the steady state distribution $\left[\pi_{0}, \pi_{1}, \ldots, \pi_{L}\right]$ also depends on $L$ only. Therefore, the equilibrium of the model can be characterized by a system of two equations, $\mathbb{Z} \mathbb{P}(L, Y)=0$ and $\mathbb{C E}(L, Y)=0$, in $(L, Y)$ space.

\section{Existence of the Equilibrium}

Before proving Proposition 1, I introduce the following Lemma:

\footnotetext{
${ }^{29}$ The derivative of $m_{x}$ with respect to $L$ is

$$
\frac{d m_{x}}{d L}=\frac{s}{x \cdot s-1}\left(\frac{x \cdot s-1}{x}\right)^{s}\left(\frac{L}{L \cdot s-1}\right)^{s} \cdot\left(1-\frac{1}{L}\right)>0 .
$$
}


Lemma 1 The sum $S \equiv \sum_{x=0}^{L} g(x) \cdot \pi_{x} \cdot I$ is increasing (decreasing) in $m_{x}$ for any function $g($.$) increasing (decreasing) in x$.

It easy to check that $\frac{d \pi_{x}}{d m_{n}}>0$ if $n \in[0,1,2, \ldots, x-1]$, and $\frac{d \pi_{x}}{d m_{n}}<0$ if $n \in$ $[x, x+1, \ldots, L-1]$. Hence:

$$
\frac{d S}{d m_{x}}=\left[\sum_{n=0}^{x} g(n) \cdot \frac{d \pi_{n}}{d m_{x}}+\sum_{n=x+1}^{L} g(n) \cdot \frac{d \pi_{n}}{d m_{x}}\right] \cdot I .
$$

The first term at the RHS is negative, the second one is positive. To check the sign of this derivative, notice that $\sum_{n=0}^{L} \pi_{n}=1$. Then:

$$
\begin{aligned}
& -\sum_{n=0}^{x} \frac{d \pi_{n}}{d m_{x}} \quad=\quad \sum_{n=x+1}^{L} \frac{d \pi_{n}}{d m_{x}} \Longleftrightarrow \sum_{n=x+1}^{L} \frac{d \pi_{n}}{d m_{x}} \Longleftrightarrow \sum_{n=0}^{L} \frac{d \pi_{n}}{d m_{x}} \cdot g(n) \\
& -\sum_{n=0}^{x} \frac{d \pi_{n}}{d m_{x}} \cdot g(n)<\quad
\end{aligned}
$$

The last inequality is verified if $g(x)$ is an increasing function.

To prove Proposition 1, I distinguish three case.

CASE 1: $s>2$.

Consider $\mathbb{Z} \mathbb{P}(L, Y)=0$. Applying the implicit function theorem, I get:

$$
\frac{d Y}{d L}=\frac{s}{2-s} \cdot\left(\frac{h}{q} \cdot \frac{r \cdot \alpha^{s-1}}{1-\beta}\right)^{\frac{1}{2-s}} \cdot s^{\frac{s}{2-s}} \cdot(L-1) \cdot L^{\frac{2(s-1)}{2-s}} \cdot(L s-1)^{\frac{1}{s-2}}<0 .
$$

The implicit function $\mathbb{Z P}(L, Y)=0$ is decreasing in the $(L, Y)$ space. I denote $Y=g_{1}(L)$ the explicit function of $\mathbb{Z} \mathbb{P}(L, Y)=0$. Then, $\lim _{L \rightarrow 0} g_{1}(L) \rightarrow+\infty$ and $\lim _{L \rightarrow+\infty} g_{1}(L)=0$.

Applying the implicit function theorem to $\mathbb{C E}(L, Y)=0$, I get:

$$
\frac{d Y}{d L}=\frac{Y^{2-s}}{s-1} \cdot I \cdot \alpha^{1-s} \cdot \sum_{x=1}^{L}\left(\frac{x \cdot s-1}{x \cdot s}\right)^{s-1} \frac{d \pi_{x}}{d L}
$$


Notice that $\frac{d \pi_{x}}{d L}=\sum_{n=1}^{L} \frac{\partial \pi_{x}}{\partial m_{n}} \cdot \frac{\partial m_{n}}{\partial L}$. The derivative $d m_{n} / d L$ is positive (see footnote 29). Therefore, the derivative in (B.3) is positive if the marginal increase in $m_{n}$ on $\sum_{x=1}^{L}\left(\frac{x \cdot s-1}{x \cdot s}\right)^{s-1} \pi_{x}$ is positive. For Lemma 1 , this is the case because the function $g(x)=\left(\frac{x \cdot s-1}{x \cdot s}\right)^{s-1}$ is increasing in $x$.

The implicit function $\mathbb{C E}(L, Y)=0$ is increasing in the $(L, Y)$ space.

I denote $Y=g_{2}(L)$ the explicit function of $\mathbb{C E}(L, Y)=0$. Then, $\lim _{L \rightarrow 0} g_{1}(L)=0$ and $\lim _{L \rightarrow+\infty} g_{1}(L)=k$, a positive and finite number, because $\lim _{L \rightarrow+\infty} \frac{L s-1}{L s}=1$.

Figure 2 (a) illustrates the equilibrium.

CASE 2: $s=2$.

If $s=2, Y$ disappears from $\mathbb{Z P}=0$, that uniquely defines the value for $L$. $\mathbb{Z P}(L)=0$ is a vertical line in the $(L, Y)$ space. It easy to see that there exists a unique equilibrium.

CASE 3: $1<s<2$.

In this case, the derivative $(B .2)$ is positive and $\mathbb{Z P}(L, Y)=0$ is increasing in the $(L, Y)$ space. Moreover, $\lim _{L \rightarrow 0} g_{1}(L)=0$ and $\lim _{L \rightarrow+\infty} g_{1}(L) \rightarrow+\infty$.

Since $\mathbb{C E}(L, Y)=0$ is also verified at the origin, the point $(0,0)$ is one equilibrium solution of the system.

Moreover, at $L \rightarrow+\infty, g_{1}(L)>g_{2}(L)=k$. So, if I show that in the interval $L \in[0,1]$ $g_{1}(L)<g_{2}(L)$, the system admits at least another equilibrium, in which the function $g_{1}(L)$ intersects the function $g_{2}(L)$ from below. See Figure $2(\mathrm{~b})$.

To prove this last point, I evaluates the derivatives in (B.2) and (B.3) at $L=0$ and $L=1$. It is easy to see that $g_{1}^{\prime}(0)=g_{2}^{\prime}(0)=0$ and $g_{1}^{\prime}(1)=0$. On the contrary:

$$
g_{2}^{\prime}(1)=\frac{\left(g_{2}(1)\right)^{2-s}}{s-1} \cdot I \cdot \alpha^{1-s} \cdot\left(\frac{s-1}{s}\right)^{s-1} \frac{d \pi_{1}}{d L}>0 .
$$

So, in the interval $L \in[0,1]$, the function $g_{1}(L)$ coincides with the horizontal axis and for $L \in(1,+\infty)$ becomes upward sloping. On the other hand, $g_{2}(L)$ is increasing for $L \in(0,+\infty)$. The function $g_{1}(L)$ intersects $g_{2}(L)$ in the positive hortant at least once.

\section{Appendix C. Shape of the Distribution}

To prove Corollary 1, consider equation (3): $\pi_{x+1}>\pi_{x} \leftrightarrow m_{x} /(x+1)>\delta$. So imposing $m_{0}>\delta$ implies that $\pi_{1}>\pi_{0}$. From the zero profit condition (17), one also 
gets that $\frac{\Delta\left[m_{x} /(x+1)\right]}{\Delta x}<0 .{ }^{30}$ So $m_{x} /(x+1)$ reaches the maximum at $x=1$ and then it monotonically decreases until it is equal to zero at $x=L$.

Since $\pi_{1}>\pi_{0}$, two cases are possible. If $m_{x} /(x+1)<\delta \forall x \in[1,2, \ldots, L-1]$, then the maximum point of the distribution $\left[\pi_{0}, \pi_{1}, \pi_{2}, \ldots, \pi_{L}\right]$ is at $x=1$ and then it monotonically decreases.

Otherwise, the distribution is increasing as long as $m_{x} /(x+1)>\delta$ and decreases for $m_{x} /(x+1) \in[0, \delta)$. Figure 3 shows it. In both cases, it is hump-shaped.

\section{Appendix D. Comparative Statics}

CASE 1: $s>2$.

Effects on $L$ and $Y$

I consider the system (18) and summarize the derivatives computed in Appendix B:

$$
\begin{aligned}
& \frac{\partial \mathbb{Z} \mathbb{P}}{\partial L}=-\frac{q}{h}(1-\beta) \alpha^{1-s} \cdot Y^{2-s} \frac{(L s-1)^{s-1}}{(l s)^{s}} \cdot \frac{s(L-1)}{L(L s-1)}<0, \\
& \frac{\partial \mathbb{Z} \mathbb{P}}{\partial Y}=\frac{q}{h}(1-\beta) \alpha^{1-s}(2-s) \cdot Y^{1-s} \frac{(L s-1)^{s-1}}{(L s)^{s}}<0, \\
& \frac{\partial \mathbb{C E}}{\partial L}=-I \cdot \alpha^{1-s} \sum_{x=1}^{L}\left(\frac{x \cdot s-1}{x \cdot s}\right)^{s-1} \frac{\partial \pi_{x}}{\partial L}<0, \\
& \frac{\partial \mathbb{C E}}{\partial Y}=(s-1) \cdot Y^{s-2}>0 .
\end{aligned}
$$

Moreover, it is easy to check that $\partial \mathbb{Z} \mathbb{P} / \partial h<0, \partial \mathbb{C E} / \partial h=0$, whereas $\partial \mathbb{Z} \mathbb{P} / \partial \beta<$ 0 , and $\partial \mathbb{C E} / \partial \beta=0$.

Applying the implicit function theorem:

${ }^{30}$ Ignoring for a moment the integer problem, one gets

$$
\frac{d\left[m_{x} /(x+1)\right]}{d x}=r \cdot(L \cdot s-1) \cdot \frac{L}{x} \cdot \frac{s}{x \cdot s-1} \cdot\left(\frac{L}{x} \cdot \frac{x \cdot s-1}{L \cdot s-1}\right)^{s-1} \cdot\left(\frac{1}{x}-1\right)<0 .
$$




$$
\frac{d L}{d h}=-\frac{\frac{\partial \mathbb{Z} \mathbb{P}}{\partial h} \cdot \frac{\partial \mathbb{C E}}{\partial Y}}{\frac{\partial \mathbb{Z} \mathbb{P}}{\partial L} \cdot \frac{\partial \mathbb{C E}}{\partial Y}-\frac{\partial \mathbb{Z} \mathbb{P}}{\partial Y} \cdot \frac{\partial \mathbb{C E}}{\partial L}}<0, \quad \frac{d Y}{d h}=\frac{\frac{\partial \mathbb{Z P}}{\partial h} \cdot \frac{\partial \mathbb{C E}}{\partial L}}{\frac{\partial \mathbb{Z P}}{\partial L} \cdot \frac{\partial \mathbb{C E}}{\partial Y}-\frac{\partial \mathbb{Z} \mathbb{P}}{\partial Y} \cdot \frac{\partial \mathbb{C E}}{\partial L}}<0 .
$$

Similarly, comparative statics on $\beta$ leads to:

$$
\frac{d L}{d \beta}=-\frac{\frac{\partial \mathbb{Z P}}{\partial \beta} \cdot \frac{\partial \mathbb{C E}}{\partial Y}}{\frac{\partial \mathbb{Z} \mathbb{P}}{\partial L} \cdot \frac{\partial \mathbb{C E}}{\partial Y}-\frac{\partial \mathbb{Z} \mathbb{P}}{\partial Y} \cdot \frac{\partial \mathbb{C E}}{\partial L}}<0, \quad \frac{d Y}{d \beta}=\frac{\frac{\partial \mathbb{Z P}}{\partial \beta} \cdot \frac{\partial \mathbb{C E}}{\partial L}}{\frac{\partial \mathbb{Z} \mathbb{P}}{\partial L} \cdot \frac{\partial \mathbb{C E}}{\partial Y}-\frac{\partial \mathbb{Z} \mathbb{P}}{\partial Y} \cdot \frac{\partial \mathbb{C E}}{\partial L}}<0
$$

\section{Effects on $E$}

I now evaluate the effects on the aggregate level of employment of a change in $h$ or $\beta$. Notice that $E$ can be written as:

$$
\begin{aligned}
E & =\sum_{x=0}^{L} x \cdot l_{x} \cdot \pi_{x} \cdot I \\
& =Y^{1-s} \cdot I \cdot \alpha^{-s} \cdot \sum_{x=1}^{L}\left(\frac{x s-1}{x s}\right)^{s} \pi_{x} \quad \text { (by using equation 12) } \\
& \left.=\alpha^{-1} \cdot \frac{\sum_{x=1}^{L}\left(\frac{x s-1}{x s}\right)^{s} \pi_{x}}{\sum_{x=1}^{L}\left(\frac{x s-1}{x s}\right)^{s-1} \pi_{x}} \quad \text { (by using equation } \mathbb{C E}=0\right) .
\end{aligned}
$$

The level of employment is a function of the endogenous variable $L$. Since $L$ decreases with $h$ or $\beta$, it remains to show the effect of $L$ on $E$.

To simplify the notations, I denote $f_{x} \equiv \frac{x s-1}{x s}, a_{x} \equiv \pi_{x} \cdot\left(\frac{x s-1}{x s}\right)^{s-1}$, and $a_{x}^{\prime} \equiv \frac{\partial a_{x}}{\partial L}$. Then:

$\frac{d E}{d L}=\frac{\left(f_{1} \cdot a_{1}^{\prime}+\ldots+f_{L} \cdot a_{L}^{\prime}\right) \cdot\left(a_{1}+\ldots+a_{L}\right)-\left(a_{1}^{\prime}+\ldots+a_{L}^{\prime}\right) \cdot\left(f_{1} \cdot a_{1}+\ldots+f_{L} \cdot a_{L}\right)}{\left(a_{1}+a_{2}+\ldots+a_{L}\right)^{2}}$

At the numerator, the terms $f_{x} \cdot a_{x}^{\prime} \cdot a_{x}$ cancel out. The numerator can be re-expressed in the following way:

$$
\sum_{x=1}^{L} \sum_{k=1}^{L-x}\left(a_{x} \cdot a_{x+k}^{\prime}-a_{x}^{\prime} \cdot a_{x+k}\right) \cdot\left(f_{x+k}-f_{x}\right)
$$

The term $f_{x+k}-f_{x}$ is positive $\forall x \in[1, \ldots, L]$ and $\forall k \in[1, \ldots, L-x]$ because $f_{x}$ is increasing in $x$. 
Consider now the term $a_{x} \cdot a_{x+k}^{\prime}-a_{x}^{\prime} \cdot a_{x+k}=$ $\pi_{x}\left(\frac{x s-1}{x s}\right)^{s-1} \cdot \pi_{x+k}^{\prime}\left(\frac{(x+k) s-1}{(x+k) s}\right)^{s-1}-\pi_{x}^{\prime}\left(\frac{x s-1}{x s}\right)^{s-1} \cdot \pi_{x+k}\left(\frac{(x+k) s-1}{(x+k) s}\right)^{s-1}$, with $\pi_{x}^{\prime} \equiv \frac{d \pi_{x}}{d L}$. From equation (3), $\pi_{x+k}=g\left(m_{x+k-1}, m_{x+k-2}, \ldots, m_{x+1}\right) \cdot \pi_{x}$ with $g($. being an increasing function of $m_{x+k-1}, m_{x+k-2}, \ldots, m_{x+1} \cdot{ }^{31}$ So:

$$
\begin{aligned}
\pi_{x} \cdot \pi_{x+k}^{\prime} & -\pi_{x}^{\prime} \cdot \pi_{x+k}=\pi_{x} \cdot\left[g^{\prime}(.) \cdot \pi_{x}+g(.) \cdot \pi_{x}^{\prime}\right]-\pi_{x}^{\prime} \cdot g(.) \cdot \pi_{x}, \\
& =\pi_{x}^{2} \cdot g^{\prime}(.)>0
\end{aligned}
$$

since $g^{\prime}(.) \equiv \sum_{n=x+1}^{x+k-1} \frac{\partial g(.)}{\partial m_{n}} \cdot \frac{\partial m_{n}}{\partial L}$ is positive.

Then, the numerator $(D .3)$ is positive and $d E / d L$ is positive. An increase in $h$ or $\beta$ reduces the aggregate level of employment via a decrease in $L$.

Effects on the real wage

Differentiating the wage equation (13) I get:

$$
\begin{aligned}
& \frac{d w_{x}}{d h}=\alpha \cdot \frac{x \cdot s-1+\beta}{x \cdot s-1} \cdot \frac{d Y}{d h}<0 \\
& \frac{d w_{x}}{d \beta}=\alpha \cdot \frac{x \cdot s-1+\beta}{x \cdot s-1} \cdot \frac{d Y}{d \beta}+\alpha \cdot \frac{Y}{x \cdot s-1} .
\end{aligned}
$$

Since $d Y / d \beta<0$, the effect of $\beta$ on $w_{x}$ cannot be ascertained.

CASE 2: $s=2$.

The only difference with respect to the case $s>2$ is that $\partial \mathbb{Z I P} / \partial Y=0$. It easy to verify that the sign of the derivatives $\frac{d L}{d h}, \frac{d L}{d \beta}, \frac{d Y}{d h}$, and $\frac{d Y}{d \beta}$ is the same as in the case $s>2$. The effect of $L$ on $E$ does not change too.

CASE 3: $1<s<2$.

When $s>2, \partial \mathbb{Z} \mathbb{P} / \partial Y>0$. Recall that the denominator of the derivatives $\frac{d L}{d h}, \frac{d L}{d \beta}$, $\frac{d Y}{d h}$, and $\frac{d Y}{d \beta}$ is:

$$
\frac{\partial \mathbb{Z} \mathbb{P}}{\partial L} \cdot \frac{\partial \mathbb{C E}}{\partial Y}-\frac{\partial \mathbb{Z} \mathbb{P}}{\partial Y} \cdot \frac{\partial \mathbb{C E}}{\partial L}
$$

Two scenarios are possible. In the equilibrium points in which $g_{1}(L)$ intersects $g_{2}(L)$ from below (like the positive one in Figure $2(\mathrm{~b})$ ), then $g_{1}^{\prime}(L)>g_{2}^{\prime}(L)$. From the formula

\footnotetext{
${ }^{31}$ For instance, $\pi_{2}=\frac{m_{1}}{2 \delta} \cdot \pi_{1}$ or $\pi_{4}=\frac{m_{3}}{4 \delta} \cdot \frac{m_{2}}{3 \delta} \cdot \pi_{1}$.
} 
of the implicit function theorem, this is equivalent to say that the denominator $(D .4)$ is negative. Then, the effects of $\beta$ and $h$ on $L, Y$, the real wage, and the level of employment have the same sign as in $s \geq 2$.

In Appendix B I proved that at least one equilibrium of this kind exists. But I cannot rule out the existence of equilibria in which in which $g_{1}(L)$ intersects $g_{2}(L)$ from above, $g_{1}^{\prime}(L)<g_{2}^{\prime}(L)$, and the denominator $(D .4)$ is positive. It is easy to see that under this scenario an increase in $\beta$ and $h$ raises $L$ and $Y$ and have a positive impact on the real wage and the level of employment.

\section{References}

Alesina, A., and R. Perotti (1997) 'The Welfare State and Competitiveness.' The American Economic Review 87, 921 - 939

Blanchard, O. J., and F. Giavazzi (2003) 'Macroeconomic Effects of Regulation and Deregulation in Goods and Labour Markets.' The Quarterly Journal of Economics 118, 879-907

Blanchard, O. J., and N. Kiyotaki (1987) 'Monopolistic Competition and the Effects of Aggregate Demand.' The American Economic Review 77, 647 - 666

Blanchflower, D., and R. Freeman (1992) 'Unionism in the United States and Other Advanced OECD Countries.' Industrial Relations 31, 56 - 79

Blankenau, W., and A. Kose (2007) 'How Different Is the Cyclical Behavior of Home Production Across Countries?' Macroeconomic Dynamics 30, 807 -842

Brock, E., and S. Dobbelaere (2006) 'Has International Trade Affected Workers' Bargaining Power?' Review of World Economics 142 (2), 233-266

Calmfors, L., and J. Driffil (1988) 'Bargaining Structure, Corporatism, and Macroeconomic Performance.' Economic Policy 6, 12 - 61

Card, D., T. Lemieux, and W. Craig Riddel (2004) 'Unions and Wage Inequality.' Journal of Labor Research 25, 519 - 569 
Carlin, W., and D. Soskice (2006) Macroeconomics: Imperfections, Institutions, and Policies (Oxford University Press)

Carruth, A., and A. Oswald (1985) 'Miners' Wages in Post-War Britain: An Application of a Model of Trade Union Behaviour.' The Economic Journal 95, 1003 1020

Clark, A., and A. Oswald (1993) 'Trade Union Utility Functions: A Survey of Union Leaders' Views.' Industrial Relations 32, 391 - 411

Delacroix, A. (2006) 'A Multisectorial Matching Model of Unions.' Journal of Monetary Economics pp. $573-596$

DiNardo, J., N. Fortin, and T. Lemieux (1996) 'Labor Market Insitutions and the Distribution of Wages: A Semi-Parametric Approach.' Econometrica 64, 1001 -1044

Dixit, A., and J. Stiglitz (1977) 'Monopolistic Competition and Optimum Product Diversity.' The American Economic Review 67, 297-308

Ebell, M., and C. Haefke (2009) 'Product Market Deregulation and the U.S. Employment Miracle.' Review of Economic Dynamics 12, 479 - 504

Fernandez, R., and D. Rodrik (1991) 'Resistance to Reform: Status Quo Bias in the Presence of Individual-Specific Uncertainty.' The American Economic Review $81,1146-1155$

Fiori, G., G. Nicoletti, S. Scarpetta, and F. Schiantarelli (2008) 'Employment Outcomes and the Interaction Between Product and Labour Market Deregulation: Are They Substitutes or Complements?' Boston College WP n. 663

Griffith, R., R. Harrison, and G. Macartney (2007) 'Product Market Reforms, Labour Market Institutions and Unemployment.' The Economic Journal 117, C142 - C166

Guadalupe, M. (2007) 'Product Market Competition, Returns to Skill and Wage Inequality.' Journal of Labor Economics 25 (3), 439 - 474

Hall, R.H., and P.R. Milgrom (2008) 'The Limited Influence of Unemployment on the Wage Bargain.' The American Economic Review 98, 1653 - 74 
INS (2000; 2001; 2002) 'Démographie des entreprises.' Institut National de Statistiques Jean, S., and G. Nicoletti (2004) 'Regulation and Wage Premia.' CEPII WP n. 12

Koeniger, W., M. Leonardi, and L. Nunziata (2007) 'Labor Market Institutions and Wage Inequality.' Industrial and Labor Relations Review 60, 340-356

Lehmann, E., and B. Van der Linden (2010) 'Search Frictions on Product and Labor Markets: Money in the Matching Function.' Macroeconomic Dynamics 14, 56 - 92

Neal, D. (1995) 'Industry-Specific Human Capital: Evidence from Displaced Workers.' Journal of Labor Economics 13, 653-677

Nicoletti, G., and S. Scarpetta (2005) 'Product Market Reforms and Employment in OECD Countries.' OECD Working Paper, No. 59.

Parent, D. (2000) 'Industry-Specific Capital and the Wage Profile: Evidence from the National Longitudinal Survey of Youth and the Panel Study of Income Dynamics.' Journal of Labor Economics 18, 306-323

Pissarides, C. (2000) Equilibrium Unemployment Theory (2nd edition, Cambridge, Mass: MIT Press.)

Rosen, A. (1997) 'An Equilibrium Search-Matching Model of Discrimination.' European Economic Review 41, 1589-1613

Samuelson, W., and R. J. Zeckhauser (1988) 'Status Quo Bias in Decision Making.' Journal of Risk and Uncertainty 1, 7-59

Spector, D. (2004) 'Competition and the Capital-Labor Conflict.' European Economic Review 48, 25-38

Taylor, H., and S. Karlin (1998) An Introduction to Stochastic Modeling (3rd edition, San Diego: Academic Press.)

Waldman, M. (1991) 'The Role of Multiple Potential Entrants/Sequantial Entry in Noncooperative Entry Deterrence.' The RAND Journal of Economics 22, 446 - 453 